\title{
Rehabilitative Approach to Rheumatological Diseases
}

\author{
Deniz EVCİK
}

Editor-in-Chief

The number of cases of rheumatological diseases, including musculoskeletal disorders, is only surpassed by cardiovascular diseases. Their prevalence in adults in Europe is about 25\%, but this rate varies according to countries. In the United States, musculoskeletal disorders affect 50 million adults, and this number is predicted to rise to more than 60 million by $2030 .^{[1,2]}$

Rheumatological illnesses can be seen in all ages but occur at an increased ratio in the elderly. In addition, they can be found in both genders, but females comprise more than $60 \%$ of the patients. Rheumatological diseases affect joint structures such as the synovium, bones, and cartilage as well as the surrounding muscles, tendons, and ligaments. ${ }^{[3]}$ As a basic classification, these diseases can be categorized into two subgroups: inflammatory and non-inflammatory, with non-inflammatory rheumatological disorders such as neck, back, and lower back pain and soft tissue diseases like fibromyalgia and osteoarthritis making up $95 \%$ of all cases. A wide range of heterogeneous disorders and clinical expressions also fall into this category, including arthritis and osteoporosis, and all involve different fundamental etiopathogeneses. Therefore, they should be treated appropriately via multidisciplinary approaches. ${ }^{[4]}$

Rheumatological diseases can be defined as chronic painful musculoskeletal disorders which result in limitations involving joint mobility, muscle weakness, inactivity, and a decline in functional capacity. The vicious cycle of pain and immobility ultimately leads to functional impairment in daily living activities. Furthermore, the combination of joint stiffness and deformities enhances the probability of having a disability along with a poor quality of life. In order to lessen the chances of this happening, complex and multidisciplinary treatments for rheumatological diseases should be employed that include both pharmacological drug therapies and nonpharmacological interventions in the early phases. ${ }^{[5]}$ The main pharmacological therapies include non-steroidal anti-inflammatory drugs (NSAIDs), corticosteroids, synthetic and biological disease-modifying antirheumatic drugs (DMARDs) for rheumatoid arthritis (RA), and intra-articular injections. Several guidelines were previously developed for the proper management of rheumatological conditions. Last year, the Turkish League Against Rheumatism (TLAR) provided recommendations for the management of osteoarthritis (OA), RA, and ankylosing spondylitis (AS) by taking into consideration the health care system of our country ${ }^{[6-8]}$ These recommendations emphasized the importance of non-pharmacological interventions. The rehabilitative treatment approach included educational programs (lifestyle alterations, weight control, joint protection, and energy consumption), physical therapy modalities [thermotherapy, cryotherapy, electrotherapy, transcutaneous electrical nerve stimulation (TENS), and laser therapy], exercise (range of motion, strengthening, stretching, flexibility, muscle conditioning, aerobics, and cardiopulmonary fitness), ergonomic arrangements, assistive and adaptive devices, protective and corrective orthoses, appropriate footwear, and hydrotherapy (balneotherapy, spa, and aquatherapy).

Overall, the treatment goal for rheumatological disorders should not be limited by only

\footnotetext{
Correspondence: Deniz Evcik, M.D. Ufuk Üniversitesi Tıp Fakültesi, Fiziksel Tıp ve Rehabilitasyon Anabilim Dalı, 06520 Balgat, Ankara, Turkey. Tel: +90 312 - 2044351 e-mail: evcikd@yahoo.com 
pharmacological therapies. We have to start nonpharmacological interventions as early as possible to prevent disability. Therefore, physical medicine and rehabilitation (PMR) has arisen as a core part of the necessary therapy. A realistic, eligible, and practical rehabilitation program involves the cooperation between the patient and rehabilitation team members. The PMR specialist, as the leader of the team, collaborates with the occupational therapist, physiotherapist, physiotherapy assistants, and orthotist in order to achieve the maximum functional capacity for their patients, and the arrangement of individual treatment programs is essential for active diseases. Rheumatologists can also consult and join the team, and particular consideration should be given to the fact that improvement of quality of life is as important as the inhibition of the inflammation. Otherwise, patients will incur an increased financial burden due to the failure of both the medical and non-medical therapies.

As a result, a good, collaborative rehabilitation team is required for the treatment of rheumatological disorders, beginning in the early phases of the diseases. Additional scientific studies are necessary in order to obtain objective data regarding the efficacy of rheumatological rehabilitation programs.

\section{Declaration of conflicting interests}

The author declared no conflicts of interest with respect to the authorship and/or publication of this article.

\section{Funding}

The author received no financial support for the research and/or authorship of this article.

\section{REFERENCES}

1. Available from: http://www.eular.org/

2. Salaffi F, De Angelis R, Grassi W; MArche Pain Prevalence; INvestigation Group (MAPPING) study. Prevalence of musculoskeletal conditions in an Italian population sample: results of a regional community-based study. I. The MAPPING study. Clin Exp Rheumatol 2005;23:819-28.

3. Uddin T, Moyeenuzzaman, Hasan SA. Rehabilitation of patients with rheumatic diseases-an update. TAJ 2003;16:82-88.

4. Forseth KO, Hafström I, Husby G, Opava C. Comprehensive rehabilitation of patients with rheumatic diseases in a warm climate: a literature review. J Rehabil Med 2010;42:897-902.

5. Maddali Bongi S, Matucci Cerinic M. Rheumatologic rehabilitation: the great expectation for rheumatic patients. Reumatismo 2012;64:1-6.

6. Ataman Ş, Borman P, Evcik D, Aydoğ E, Ayhan F, Yildizlar D, et al. Management of rheumatoid arthritis: consensus recommendations from the Turkish League Against Rheumatism. Turk J Rheumatol 2011;26:273-94.

7. Tuncer T, Çay HF, Kaçar C, Altan L, Atik OS, Aydın AT, et al. Evidence-based recommendations for the management of knee osteoarthritis: a consensus report of the Turkish League Against Rheumatism. Turk J Rheumatol 2012;27:1-17.

8. Bodur H, Sivas F, Yılmaz O, Özgöçmen S, Günaydın $\mathrm{R}$, Kaya $\mathrm{T}$, et al. Turkish League Against Rheumatism national recommendations for the management of ankylosing spondylitis. Turk J Rheumatol 2011;26:173-86. 